\title{
The Effect Of The Knowledge Of Menstrual Management On The Reactions To Its Onset: A Study On Urban Areas Of Pakistan
}

\author{
Khalida Rauf \\ Department of Psychology \\ Federal Urdu University for Arts, Science and Technology \\ Sheeba Farhan \\ Department of Psychology \\ University of Karachi
}

\begin{abstract}
The purpose of the present study was to investigate the effect of first menstrual onset on females with reference to Pakistani culture. Two hundred and thirty five female students from Karachi University were selected on the basis of simple random sampling. Structured instructions and questionnaire was used in face to face interview for evaluating the average age, educational level, place of occurrence and degree of awareness of first and later born females at the time of first periods. Survey also compares the type of information and perception of occurrence of first period. Furthermore, emotional feelings of aware and unaware females at the time of first onset and current state of menstruation cycle have been evaluated. Comparison between the education of mother and degree of awareness is also assessed. Chi square was applied for interpretation of results.
\end{abstract}

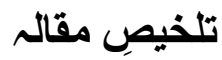

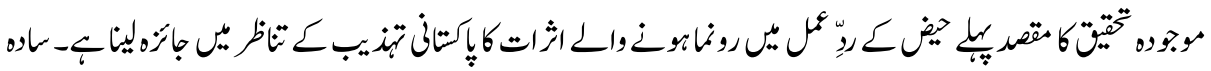

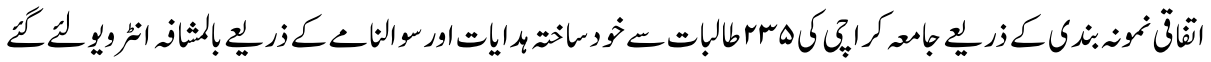

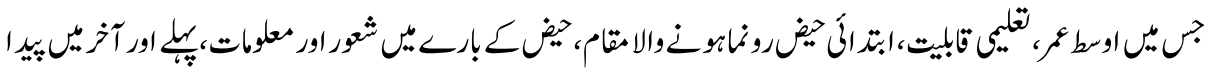

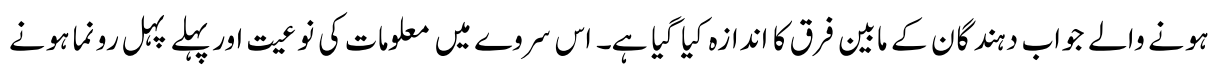

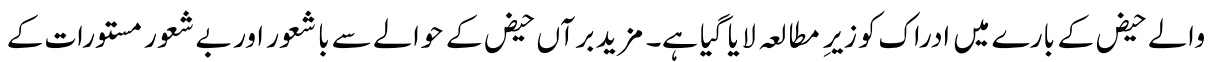

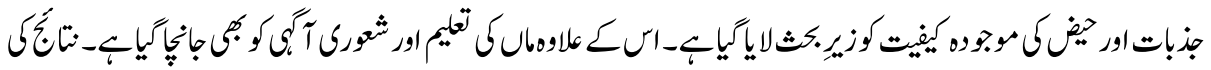

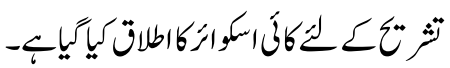

\section{Introduction}

Menstruation is monthly shedding of blood from the uterus lining, which exits through cervix and vagina. It provides important hormones to female body. It prepares the body 
for pregnancy each month. The average menstruation cycle is 28 days in adults and from 21 to 45 days in young teens. ${ }^{1}$

Menstruation takes place after the occurrence of puberty. Adolescent girls differ widely with regard to the onset of puberty. At another place Malina (1990) reported early changes in breast and pubic hair followed by growth spurt. First menstruation is mostly known as menarche, usually occurs after 2 years of invisible physical changes. It may occur between $12 \frac{1}{2}$ and $13 \frac{1}{2}$. Most girls experience this event between the age of 11 and 15 .

The average difference in the timing of menarche occurs in identical twins is 2 months, whereas, for fraternal twins is 8 months (Marshells \& Tanner, 1974). The timing of menarche has undergone various changes like during 1840's it was roughly about 17 but with the emergence of industrialization till 1950's it dropped at faster pace ie; 4 months per decade, which Roche (1979), called secular trend which is largely caused by dietary changes, increase in protein and fat intake, reduction in physical activity.

Warren, Brooks, Fox, Lancelot, Newman \& Hamilton (1991) reported later occurrence of menarche among adolescent dancers, Calabresa, et.al. (1983) reported same pattern among adolescent girls who participate in physical exercise.

Gould \& Gould (1932) compared two successive generations for the onset of menarche, they found resemblance between the two generation. At another place, Ponta, et.al. (2005) reported the same in their longitudinal study in Finland.

Imelda in 2000 examined the ways in which menstrual knowledge is transmitted to younger generation. The author found that in African American families, mothers use story telling based on their experiences to accomplish sexual education among their daughters.

According to Water Aid Program 2012, Massey, 2011 reported that women in Uganda expressed feelings of shame associated with menstruation and in Nepal girls are made to sleep alone, which identified them as going through menstrual period. Keeping the girls in isolation is again violation of human rights.

According to WSSCC report 2013, women in Bangladesh do not work during menstruation, which means 6 to 7 unpaid days, due to lack of sanitation facilities. If workforce's menstrual needs are addressed properly it may result in low absenteeism and productivity gains.

\section{Literature Review}

Menstruation is an integral part of women's life, it must be treated with pride and given priority in hygiene education (De Albuquerque,2012). Many Asians and Sub Saharan African societies girls' knowledge of menstruation is low. 
Shukla (2005) reported that menstruating girls are not touched even in big cities in general ignorance about this physiological process. This ignorance and myth compound the problem and keep menstrual needs unaddressed.

Ching \& Chih (2008) studied menstrual knowledge and menstrual health case behaviors of $5^{\text {th }}$ graders of Taiwan region, $45.1 \%$ was the correct response rate for menstrual knowledge questionnaire. $78.8 \%$ of the respondents said that menstruation had influence on their emotions.73\% believed that it affected their daily life, $61.6 \%$ believed that it affected their school life and $50.1 \%$ believed that it affected their social interaction. The authors reported girls who had been prepared by adults for menarche, they scored well on menstrual knowledge questionnaire.

In 2012, Jarrah \& Kamel reported that girls not prepared for menstruation and low menstrual practices were found to be significantly correlated with inadequate premenstrual preparation. The study emphasizes the need for premenstrual knowledge in order to have positive attitude toward menstruation.

Chang, Tung \& Chih (2008) said that their respondents reported that menstruation had an influence on their emotions. Green (2009) reported that girls viewed menstruation as a stressor in their lives particularly toward schooling. The same has been reported by Angier (1999). It not only affects their social lives but also change their perception of themselves. Sommer (2009a); Sommer \& Kirk (2008); Sommer, (2009b) reported that girls view menstruation as barrier to education and careers. Moreover, Thomas (2002) reported menstruation as the cause of dropout from school during puberty. These outcomes are generally related to the unavailability of napkins or unpredictability of the cycle, whom Scott, Droopson, Montgomery, Dolan \& Ryus (2009) used interventions like providing free sanitary napkins resulted in dropping of absence rate from school, negative feelings and embarrassment decreased. Not only this much, rather feelings of shame and sadness also decreased. According to WSSCC report 2012, girls should be given privacy and sufficient water and place to dispose off napkins in school. This availability will reduce their absence rate and prevent them to be at the disadvantage ( World Toilet Day Advocacy Report, 2012).

McMahon, Winch, Caruso, Obure, Ogutu, Ochari \& Rheingans (2011) reported that this topic is related to the feelings of shame, fear, distraction, and confusion and powerless. It is also associated with the fact that menstruation is considered taboo and it is observed that there is social pressure to maintain secrecy. One of the respondents reported that menstruation in school means something sexual that is why it is considered taboo. In the same study, social prohibition like not entering into parent's sleeping area, not washing family water pot are applied to menstruating girls. A significant change in behavior occurs in school ie; they avoid sitting so their shirts may not be soiled. These girls also asked their friends to walk closely behind them so their stains may not be visible. Several coping mechanisms have been reported by these girls. Ali \& Rizvi (2009) reported that 
fear and worry as a reaction to menarche among students in Karachi. In addition to this, Khanna \& Bhaswar (2005) found that girls reported worried, wept, fear and shame and discussed this issue with their mothers. Indian girls also reported limitations on engaging in household chores due to the uncleanliness associated with it.

As there are gaps in menstrual knowledge reported in above mentioned studies, the present study is done with the rationale to decipher those myths. As the problem is prevalent in third world countries, it is imperative that first those myths be identified and later rectified. Issues of reproductive health have been studied widely throughout the world even in third world countries like Kenya, Tanzania, Nigeria, India, and very little in Pakistan. Keeping the dearth of literature, it was imperative to explore the area of reproductive health, particularly menstruation because this topic is not openly discussed in Asian and Islamic society like Pakistan.

The following hypotheses were framed

1. There will be a difference in the awareness level of first and later born.

2. There will be a difference in the percentage of the type of information received by first born and later born.

3. There will be a difference in the percentage of the person in whom the girls confide.

4. There will be a difference among the percentage of the females regarding the perception of the first menstrual cycle.

5. There will be a difference among the percentage of psychological feelings of the aware and unaware females.

6. There will be a difference among the percentage of physical feelings of the aware and unaware females.

7. There will be a difference in the educational levels of mothers and the degree of awareness among girls.

\section{Methodology}

\section{Sample}

The sample comprised of 235 female students from the University of Karachi. Random sampling method was used.

\section{Procedure}

After assuring confidentiality, the demographic information form was administered for gauging information on age and educational level of mothers and birth order. Structured instructions and questionnaire was used in face to face interview for evaluating the place of occurrence and degree of awareness of first and later born females at the time of first periods. 


\section{Statistical Analysis}

In order to calculate percentages of all responses Chi square was applied through SPSS 15.00 .

\section{Results}

Table 1

Average Age and Grade at the Time of First Onset

\begin{tabular}{|l|c|}
\hline \multicolumn{1}{|c|}{ First onset } & Averages \\
\hline Age $\mathrm{N}=235$ & 13.65 \\
\hline Educational grade $\mathrm{N}=235$ & 7.8 \\
\hline
\end{tabular}

According to the table 1, average age and educational grade at the time of first onset of the period is found to be 13.65 and 7.80 respectively.

Table 2

Percentage of Place of Occurrence

\begin{tabular}{|l|c|c|c|}
\hline Place of Occurrence & Home & School & Others \\
\hline Total & 189 & 38 & 8 \\
\hline Percentage & $80.4 \%$ & $16.1 \%$ & $3.5 \%$ \\
\hline
\end{tabular}

Table 2 shows the percentage for place of occurrence of first period, which is significantly high for home that is $80.42 \%$, the percentage for the occurrence at school and the other place is very low, that is, $16.17 \%$ and $3.5 \%$ respectively which shows that majority of females had their first period at home.

Table 3

Degree of Awareness in First and Later Born

\begin{tabular}{|c|c|c|c|c|c|}
\hline \multicolumn{3}{|c|}{ First born } & \multicolumn{3}{c|}{ Later born } \\
\hline & Total=82 & percentage & & Total=153 & percentage \\
\hline Aware & 32 & $39 \%$ & Aware & 54 & $35.7 \%$ \\
\hline Not aware & 50 & $60 \%$ & $\begin{array}{c}\text { Not } \\
\text { aware }\end{array}$ & 99 & $64.2 \%$ \\
\hline
\end{tabular}

Table above shows the comparisons of the degree of awareness between first and later born. Among 82 first born females 39\% were aware and 60\% were not aware and among 153 later born females $35.7 \%$ were aware and $64.2 \%$ were not aware. It shows that there is no major difference in awareness between first and later born. 
Table 4

Comparison of Type of Information between First and Later Born in Percentage

\begin{tabular}{|c|c|c|c|c|}
\hline Birth order & aware & Religious & Social & biological \\
\hline First born & $31 \%$ & $84.37 \%$ & $43.75 \%$ & $37.50 \%$ \\
\hline Later born & $35.76 \%$ & $70.37 \%$ & $55.55 \%$ & $44.40 \%$ \\
\hline
\end{tabular}

\begin{tabular}{|c|c|c|c|c|}
\hline Birth order & Not aware & Religious & Social & biological \\
\hline First born & $60 \%$ & $62.0 \%$ & $16.0 \%$ & $22.0 \%$ \\
\hline Later born & $64.2 \%$ & $65.60 \%$ & $48.40 \%$ & $48.40 \%$ \\
\hline
\end{tabular}

Table 4 mentions the type of information among first and later born, both aware and not aware females' .among aware females 39\% were first born and 35.76\% were later born. For aware females, the extent of religious knowledge was $84.37 \%$ and $70.37 \%$ for first and later born respectively. Similarly $43.75 \%$ first and $55.55 \%$ of later borns were found to be aware of social aspects and $37.5 \%$ of first born and $44.4 \%$ of later born were aware of biological knowledge.

Among not aware females 60\% were first born and 64\% were later born.

For not aware females, the religious knowledge was $62 \%$ and $65.60 \%$ for first and later born respectively. Similarly $16 \%$ first and $48.40 \%$ of later born were found to be aware of social aspects and $22 \%$ of first born and $48.40 \%$ of later born were aware of biological knowledge.

Table 5

Percentages of Confide in

\begin{tabular}{|c|c|c|c|c|c|}
\hline Confide in & mother & sister & friend & aunt & Grand mom \\
\hline percentage & $62.66 \%$ & $28.80 \%$ & $3.69 \%$ & $1.45 \%$ & $2.70 \%$ \\
\hline
\end{tabular}

Table 5 is showing the percentages of those people in which females confide at the time of first onset of menstruation cycle. $62.66 \%$ females confide in their mothers, $28.80 \%$ confide in sister, $3.69 \%$ in friend, $1.45 \%$ in aunty and $2.70 \%$ in their grandmother. It shows that majority of the females confide in their mothers.

Table 6

The Perception of Occurrence in Percentage

\begin{tabular}{|c|c|c|c|}
\hline & early & late & normal \\
\hline Total $=235$ & 68 & 22 & 142 \\
\hline percentage & $28.9 \%$ & $9.36 \%$ & $60.42 \%$ \\
\hline
\end{tabular}

Table 6 shows the perception of females about their perception of occurrence is $60 \%$ 
Table 7

The Average Age Considered as Median (13.65) then how many fall Above and Below it, According to the Perception of Occurrence

\begin{tabular}{|c|c|c|c|c|}
\hline Age range & No. of cases & \multicolumn{3}{|c|}{ Perception of occurrence } \\
\cline { 3 - 5 } & & Early $=68$ & Late $=22$ & Normal=42 \\
\hline 10 & 8 & 3 & 0 & 5 \\
\hline 11 & 13 & 6 & 0 & 7 \\
\hline 12 & 51 & 21 & 5 & 25 \\
\hline 13 & 70 & 16 & 6 & 48 \\
\hline 14 & 62 & 15 & 6 & 41 \\
\hline
\end{tabular}

Table 8

Psychological Feelings at the Onset of First Periods

\begin{tabular}{|l|c|c|c|c|c|c|c|c|c|c|}
\hline $\begin{array}{l}\text { Psychol } \\
\text { ogical } \\
\text { feelings }\end{array}$ & $\begin{array}{c}\text { Bad } \\
\text { Sad } \\
\text { Low }\end{array}$ & $\begin{array}{c}\text { Upset } \\
\text { Disturb } \\
\text { Anxious } \\
\text { Irritate } \\
\text { Nervous Cry }\end{array}$ & $\begin{array}{c}\text { Confused } \\
\text { Uncertain } \\
\text { Curious }\end{array}$ & $\begin{array}{c}\text { Surprised } \\
\text { Shocked }\end{array}$ & $\begin{array}{c}\text { Afraid } \\
\text { Feeling of } \\
\text { dying } \\
\text { Frighten }\end{array}$ & $\begin{array}{c}\text { Happy } \\
\text { Excited }\end{array}$ & $\begin{array}{c}\text { Shy } \\
\text { Embarrass }\end{array}$ & $\begin{array}{c}\text { Anger } \\
\text { Hated }\end{array}$ & $\begin{array}{c}\text { Dirty Disgusting } \\
\text { Dang }\end{array}$ & $\begin{array}{c}\text { Normal } \\
\text { AW\% }\end{array}$ \\
\hline $\begin{array}{l}\text { N. } \\
\text { AW\% }\end{array}$ & 9.13 & 37.18 & 5.13 & 6.41 & 11.54 & 3.85 & 2.56 & 2.56 & 6.41 & 19.23 \\
\hline
\end{tabular}

Table 9

Physical Feelings at the Onset of First Periods

\begin{tabular}{|c|c|c|}
\hline Physical feelings & unwell & Well \\
\hline AW\% & 59.3 & 40.69 \\
\hline N.AW\% & 59.73 & 40.26 \\
\hline
\end{tabular}

\section{Discussion}

The present study attempts to explore different variables associated with menstruation such as knowledge of menstrual management, sources of information, mean age, and mean educational level of girls, perception regarding the occurrence of menstrual cycle. Moreover, physical and psychological reactions are explored. Furthermore, how far mother's educational level created awareness among girls.

The mean age at which menstruation occurs has been reported as 13.65, Table No 1 . These girls have been mostly the student of seventh or eighth grade. Even though the onset of menarche is reported as earlier due to numerous factors, but Paula \& Adams (2002) reported that despite controversy the age of menarche has remained constant.

Table No 2 shows percentages for the place where first menstruation occurs, which 80.4\% is for home and $16.1 \%$ for school and $3.5 \%$ for other places. This happens mostly, because we spent most of our hours at home and only five to six hours in school. 
Table No 3 compares the awareness level of first born and later born, which was $60 \%$ for first and $64.2 \%$ for later born, as to the unaware of menstruation, it was $39 \%$ and $35.7 \%$ for first and later born respectively. This result could be attributed to the fact that mothers, somehow, try to educate the first born whereas, they leave this task for older sisters for later born. Furthermore, both the birth orders in the unaware group received different kinds of information regarding the occurrence of menstruation. The highest type of information received by both the groups is reported to be religious ie; $84.37 \%$ and $70.37 \%$ respectively, the second highest type of information is social in nature, and the lowest type of information is reported to be biological in nature. The sequence of the type of information is same for unaware group. As our society is basically patriarchal and Islamic in origin, people hardly take things from biological perspective as objective approach rather religious ideas associated with menstruation are considered more acceptable, whereas, social information is mostly handed down by grandmothers. Whereas, Singh (2006) reported mothers as the primary source of information for girls, $72 \%$ received information from friends, $17 \%$ from female relatives. The same has been reported by George (1994), Joshi, Kurien, Misra, Rajeshwari \& Biswas (1998) \& Garg, Sharma \& Sahay (2001). Similar results have been obtained in our study, where $62.66 \%$ confide in mothers, $28.8 \%$ in sisters, $3.69 \%$ in friends, $1.45 \%$ in aunt and $2.7 \%$ in grandmothers, table 5.

In present sample, $60.42 \%$ of female respondents thought that the occurrence of their menstrual cycle is normal followed by $28.9 \%$ as early occurrence and $9.36 \%$ as late occurrence, table 6 .

These types and sources of information lead female respondents to acquire various prescription, taboos, and rituals, what to eat, what not to eat, what to do and what not to do during these days. As they mature further they develop different beliefs regarding what causes early menstruation (Singh, 2006).

Table No 7 reported their psychological and physical reaction s toward menstruation. The unaware group reported more negative feelings at the first onset of menstruation whereas; unaware group reported more normal feelings, ie; $19.32 \%$. With regard to physical reactions, Table No 8 , both the groups reported similarly that they felt unwell at the onset of the menstruation. They collectively think that it is something bad. It is also reported to be associated with sex which again is considered forbidden. Religious prohibitions like not offering prayers or not keeping fasts during Ramadan gives cue about their menstruation, which gives rise to their embarrassment. Moreover, Khanna et al (2005) reported that these girls wept due to fear. In Kenyans and Indian sample girls reported restrictions in their activities which pointed their menstruating condition which makes them embarrassed, when associated with many negative feelings, it automatically gives rise to anger and disgust because it disturbs their routine (Singh, 2006). 
In order to explore the educational level of mothers to see how far it affects the awareness level among girls. Results show that despite educational level there is a wide difference between aware and not aware group, percentages significantly higher for unaware group, Table No 9. Since the topic revolves around the concept of dirt and taboo, it is not discussed openly rather it needs change in social attitudes to be discussed. Even from Islamic perspective menstruation is considered impure; during this period husbands and wives do not relate physically, all these negative connotation of menstruation make sit something prohibited that is why even mothers prefer less to talk about it. As symbol of respect there is a gap between parents and children which keeps girls unaware of this fact of their lives. Singh (2006) reported that most mothers said that it is in the hands of nature.

At last, Table No 10 shows how these girls perceive their current state which $81.27 \%$ reported it as regular and $18.73 \%$ reported as irregular.

Many existing taboos keep young girls at disadvantage, when their right to knowledge is accepted only then these taboos can be broken. If this knowledge is included in their curricula as policy implication, young girls will enter this stage with full preparation rather than with shame and guilt.

\section{Limitations}

The study was conducted in one institution of urban area, where most of the girls were getting education at BS or Masters Level, it would be more informative if different segments of society, particularly low income class and females of different educational levels are incorporated into study, the results would be generalized more easily.

\section{Recommendations}

Overall results make it imperative that fears regarding menstruation should be dispelled from minds of girls. It should be instilled in their minds that these are normal processes and everybody's body goes through these experiences. It is their body, they own it, accept it as it is. Once the acceptance has taken place, it will enhance their self esteem. Consequently, not leading to negative affective states like fear, shame and guilt, once these feelings are managed, this will not hamper with their proper management of menstruation.

In every school, there should be a teacher or a big sister who could educate girls regarding menstruation (McMahan et al, 2011). It is also possible at community level, where families are incorporated to educate their girls about menstruation. It will help develop an objective and positive outlook toward this issue. 
Hygiene promotion training program be included in teachers' training curricula for all teachers and at the national level( Growing up without WASH 2013).

\section{Conclusions}

The overall results show that mostly girls are not aware of the pros and cons of menstruation that is why they report different psychological and physical reaction towards it other than normal. Since it is considered a kind of taboo that even educational level of mothers do not seem to affect it, rather religious and social channels seem to dominate the source of information about it. The biological aspect however is ignored as reproductive health issues like pregnancies, abortions and menses are not openly and properly attended to. The awareness of change in bodily state is not determined by physical process rather by the attention we pay to it( Usher p252). Since the attitude is one of negligence and ignorance towards reproductive, these issues get little attention.

WASH, United States has launched a movement to create global awareness regarding menstruation by announcing $28^{\text {th }}$ May2014 as the MHM menstrual hygiene movement (Keiser, 2013).

\section{End Notes}

$1 \quad$ (www.nlm.nih.gov)

\section{References}

Ali, T.S. \& Rizvi, S.N. (2009). Menstrual Knowledge And Practices Of Female Adolescents In Urban Karachi, Pakistan. Journal of Adolescence.

Angier, N. (1999). Women: An Intimate Geography. New York: Houghton Mifflin Company

Brooks-Gunn, J. (1987). Pubertal Process And Girl's Psychological Adaptation. In R. Lerner\& T.T Foch (Eds) Biological, Psychosocial interactions in early adolescence; A life span perspective. Hillsdale,NJ: Erlbaum.

Calabresa, I.H, Kirkendall, D.T., Floyd, M., Rapoport,S., Willliams, GW., Weiker, G.F., \& Bergfield,J.A. (1983). Menstrual Abnormalities, Nutritional Patterns, And Body Composition In Female Classical Ballet Dancers, Physician And Sport Medicine, 11, pp, 86-98.

Chang, Tung, Yu. \& Chih, Y. (2008). Menstrual Health Care Behavior And Associated Factors Among Female Elementary Students In The Haulien Region. Vol, 16 (1). 
Garg,S,. Sharma,N., \& Sahay,R., (2001). Sociocultural Aspects Of Menstruation In An Urban Slum In Dehli, India. Reproductive Health Matters,; 9; pp, 15-25.

Gender Discrimination In Education: The Violation Of Rights Of Women And Girls. Global Campaign For Education, February 2012.

George. A. (1994). It Happens To Us. In Listening To Women Talk About Their HealthIssues And Evidence From India. J. Gittelsohn et al (Eds) New Dehli, Har Anand publications, $\quad \underline{w w w . i j c m . o r g . i n / a r t i c l e . a s p ? i s s n=0970-0218 ; ~}=2006 ; \mathrm{vol}=31 ;$ issue $=$ 1 ; spages 10; epage $=14 ;$ aulast $=$ singh $\# \mathrm{ft} 1$

Gould, H.N. \& Gould, M.R. (1932). Heritability Of Age At Menarche In Girls From Fels, A Longitudinal Study. Journal of American Medical Association.98. pp, 1341-1352.

Green, L. (2009). SWASH+ Applications of Lesson learned to current and future practices SWASH+ programmatic Management Group Meeting: 2009: Tom Mboya Laboux college, Kisumu, Kenya.

Growing up without WASH, Water Aid, http://old.wateraid.org/document/rowing up without wash report final for circulation 2.pdf

Hillar, P. J. \& Adams, MD (2000). Menstruation in Young girls: a Clinical Perspective. Vol 99. Issue4. http://journals.lww.com/greenjournal/Abstract/2002/04000/ Menstruation in Young_Girls A Clinical.28.aspx, http://k1.ioe.ac.uk/schools/ efps/GenderEduDev/Equals\%20Issue \%20No.\%2015.pdf)

Imelda, N. (2000). African American Mothers use stories for Family Sexuality Education. Feb, vol.25 (1). www.journals./ww.com/menjournal/abstract/2000/01000.aspx

Joshi, A, Kurien, E., Misra, A., Rajeshwari, M., \& Biswas, S. (1998). Socio Cultural Implication Of Menstruation And Menstrual Problems On Rural Women's Lives And Treatment Seeking Behavior. Operation Research Group, Baroda. (Unpublished Ford Foundation supported study).

Keiser, D. (2013). How Menstruation - Themed Social Media Campaign Spurred A Movement For A Global Awareness Day. Period. In impatient optimists by Gates Foundation.org.

Khanna, A., Goyal,R.S \& Bhasear, S.B. (2005). Menstrual Practices And Reproductive Problems: A Study Of Adolescent Girls In Rajasthan. Journal Of Health Management.7.(1): 91-107. DOI: 10.1177.097206340400700103. [Cross Ref] 
Kolk, A. (2000). Women And Somatic Distress. Women's Health: Contemporary International Perspectives by Ussher,J., British Psychological Society, UK.

Malina, R.M. (1990). Physical Growth And Gullotta (Eds). From Childhood To Adolescence: A Transitional Period, Newbury Park.CA: Sage, pp, 41- 62.

Marshell, W.A. \& Tanner, J.M. (1974). Puberty. In J.A Davis \& J. Dobbling (Eds). Scientific Foundations of Pediatrrics. Pheladelphia; Sannders.

Marshell, V, W. \& Levy, J.A. (1990). Aging and Dying. In R.H. Binstock \& L.K.George (Eds) Handbook of Aging and Social Sciences ( $3^{\text {rd }}$ ed, pp 245-260) San Diego, CA: Academy press.

Massey. K. (2011). Sanitation, Safety and Shame. A Qualitative Study Examining The Impact Of Inadequate Sanitation On Women In The Urban Slums Of Kampala, Uganda, MSc dissertation, unpublished.

Ponta,A., Jarvelin, M.R.., Hemminki, E., Sonio, U., \& Hartikainen, A,L. (20005). Mothers And Daughters: Intergenerational Patterns Of Reproduction. European Journal Of Public Health. April 2005. 15 (2): pp, 195-199. DOI.10,1093/ eurpub.ckio38.

Reilly, J. (2000). PMS: Research Balancing The Personal With The Political Women's Health: Contemporary International Perspectives by Ussher, J., British Psychological Society, UK.

Roche, A.F, (1979). Secular Trends In Human Growth, Maturation And Development. Monographs Of The Society For Research In Child Development. 44 (3-4 serial) No. 179.

Ruble, D.N., \& Brooks-Gunn, J. (1982). The Experience Of Menarche. Child Development Analysis Of The Role Of Social Comparison In Self -Evaluation, Child Development, 53, pp, 1557-1666.

Scott,L., Dospin, S., Montgomery, P., Dolan, C. \& Ryus, C. (2009). Impact Of Providing Sanitary Pads To Poor Girls In Africa, University of Oxford.

Shukla, S. (2005). Working On Menstruation With Girls In Mumbai, India: Vacha Women's Resource Centre EQUALS, 915) p, 5. 
Singh, A.J. (2006). Place Of Menstruation In The Reproductive Lives Of Women Of Rural North India, Indian Journal Of Community Medicine, pp, 31-104.

Sommer, M. (2010). Where The Education System And Women's Bodies Collide: The Social And Health Impact Of Girls' Experiences Of Menstruation And Schooling In Tanzania. Journal of Adolescence 2010; 33 94): pp, 521-529. Doi: 10.1016/j adolescence.2009.03.008.

Sommer, M. \& Kirk, J. (2008). SWASH in Schools. Notes and News. Volume April IRC and UNICEF; 2008. 'Menstruation Is On Her Mind'; Girl-Centered, Holistic Thinking For School Sanitation; pp, 4-6.

Sommer, M. (2009). Ideologies Of Sexuality, Menstruation And Risk: Girls' Experience Of Puberty And Schooling In Northern Tanzania. Cult Health Sex.2009; 11(4): pp, 383-398. DOI:10.1080/13691050902722372. [Pub Med]\{Cross Ref]

Thomas, E. (2002). In Special Publication. No23. Publication C, Editor. Baltimore: Johns Hopkins University, Centre for Communication Program, Population Communication Services; Washington DC.

The Academy for Educational Development (2002). Healthy Futures, Reducing Barriers to Primary School completion for Kenyan Girls.

Warren, M.P, Brooks-Gunn, J, Fox, R., Lancelot, C., Newnon, D., \& Hamilton, W.G. (1991). Lack Of Bone Accretion And Menarche In Young Dancers. Evidence For A Relative Osteopenia In Weight Bearing Bones. Journal Of Clinical Endocrinology And Metabolism. 72. pp, 847-853.

Wateraid in Nepal (2009). Is Menstrual Hygiene And Management An Issue For Adolescent School Girls: A Comparative Study Of Four Schools In Different Settings Of Nepal.

\section{Webliography}

www.impatientoptimists.org.Posts/2013/07

www.journals.lww.com/jnr.twno.abstract/2008/0300/menstrualHealthCareBehandassocia ted.3.apsx

www.nlm.nih.gov/medlineplus.menstruation/html. 
112 The Effect of the Knowledge of Menstrual Management on the Reactions to its Onset: A Study on Urban Areas of Pakistan

www.wateraid.org/what-we-do/our-approach/research-and-publications/view-publication\% www.wsscc.org/topics/hygiene/menstrual-hygiene-management

Khalida Rauf is Assistant Professor in the Department of Psychology, Federal Urdu University for Arts, Science and Technology, Karachi.

Sheeba Farhan is M.Phil Research Scholar in the Department of Psychology, University of Karachi. 